\title{
Kappa opioid receptor agonists suppress absence seizures in WAG/Rij rats
}

\author{
B. Przewłockaa, W. Lasońa, H. Machelskaa, G. van Luijtelaarb, A. Coenen ${ }^{b}$, R. Przewłockia,* \\ ${ }^{a}$ Neuropeptide Research Department, Institute of Pharmacology, Polish Academy of Sciences, 12 Smętna Street, 31 -343 Kraków, Poland \\ ${ }^{\mathrm{b}}$ Institute of Psychology, University of Nijmegen, Nijmegen, The Netherlands
}

Received 7 November 1994; revised version received 11 January 1995; accepted 11 January 1995

\begin{abstract}
Involvement of the $\kappa$ opioid receptor in the regulation of epileptic activity was studied in WAG/Rij rats, a genetic model of absence epilepsy. I.c.v. administration of the $\mathcal{\kappa}$ agonists $\mathrm{U} 50,488 \mathrm{H}$ (trans-3,4-dichloro- $N$-methyl- $N$-[2-(1-pyrrolidynyl)-cyclohexyl]benzeneacetamide $\}$, U69,593 $(5 \alpha, 7 \alpha, 8 \beta)-(-)-N$-methyl-(1-pyrrolidinyl)-1-oxaspiro(4,5)dec-8-yl)benzeneacetamide) or PD117,302 (( \pm )-trans- $N$-methyl- $N$-[2-(1-pyrrolidinyl)-cyclohexyl]benzo[b]thiophene-4-acetamide), 50 and $150 \mu \mathrm{g} / 5 \mu \mathrm{l}$ each, dose-dependently decreased the number and mean duration of spike wave discharges (SWD). Peripheral administration of U50,488H (10 and $30 \mathrm{mg} / \mathrm{kg} \mathrm{s.c.)}$ also attenuated the seizure activity in this model. The specific $\kappa$ opioid receptor antagonist nor-binaltorphimine (Nor-BNI, $10 \mu \mathrm{g} / 5 \mu 1$ i.c.v., $18 \mathrm{~h}$ before EEG registration) moderately increased the number of SWD, which suggests that endogenous opioids acting through $\kappa$ receptors may tonically inhibit the seizure activity in these rats. In addition, the enhancement of an absence-like seizure activity induced by the specific $\mu$ opioid receptor agonist $\mathrm{D}$-Ala ${ }^{2}-N$-methyl-Phe ${ }^{4}-G l y^{5}$-ol-enkephalin (DAMGO, $0.7 \mu \mathrm{g} / 5 \mu \mathrm{l}$ i.c.v.) was also attenuated in rats pretreated with $\mathrm{U} 50,488 \mathrm{H}, \mathrm{U} 69,593$ or PD117,302. These data indicate that activation of the $\kappa$ opioid receptor exerts an inhibitory effect on absence-like seizure activity in WAG/Rij rats.
\end{abstract}

Keywords: Absence epilepsy; WAG/Rij rats; U50,488H; U69,593, PD117,302; D-Ala ${ }^{2}-N$-methyl-Phe ${ }^{4}$-Gly ${ }^{5}$-ol-enkephalin

Opioids exert both pro- and anticonvulsant effects depending on the seizure model, animal species, route of drug administration and, most importantly, on the type of the opioid receptor involved $[2,14,15]$. In this respect a new generation of $\kappa$ opioid receptor agonists deserves attention, since these compounds show consistent anticonvulsive properties in several models of generalized tonic-clonic and limbic seizures $[12,17,20]$. In contrast, a possible role of $\kappa$ opioid receptors in the regulation of non-convulsive generalized seizures (absence seizures) remains unclear. In the test for screening potential antiabsence drugs for fluorothyl-induced seizures, the specific $\kappa$ opioid agonist U50,488H was not effective [17]; on the other hand, the endogenous $\kappa$ receptor agonist dynorphin suppresses pentetrazole-induced seizures [13]. Corroboration of the effectiveness of $\kappa$ opioid receptor agonists in absence seizures could be attained by experiments on animals with spontaneous absence seizures. It has been proposed that WAG/Rij rats, which spontaneously show trains of $7-10 \mathrm{~Hz}$ spike-wave discharges

\footnotetext{
* Corresponding author, Fax: +4812374500 .
}

(SWD) in the cortical EEG $[1,9,19]$, are a suitable genetic model of human absence epilepsy, which has been validated by pharmacological studies [9]. We showed previously that stimulation of the $\mu$ opioid receptor in these rats strongly potentiated the number of SWD whereas the $\delta$ opioid receptor appeared not to be involved [6]. On the other hand, agonists of $\kappa$ opioid receptor showed anticonvulsant effects in various convulsive seizure models $[12,13,17,20]$, however, their role in non-convulsive epilepsy has not been studied as yet. Therefore, in the present study we investigated the involvement of $\mathcal{\kappa}$ opioid receptor in the regulation of absence-like seizures in WAG/Rij rats.

Male, 6-month-old, epileptic WAG/Rij rats, weighing $250-325 \mathrm{~g}$, kept in an animal house on a reversed 12/12 light-dark cycle (lights on at $2000 \mathrm{~h}$ ), were used as experimental subjects. During the experiment, the rats were housed singly, one to a cage, and the investigations were carried out in the dark period (red light), between 0900 and $1600 \mathrm{~h}$. They had free access to standard laboratory food and water. The rats were implanted with cortical electrodes (Plastics One, MS 333/2-A) and an i.c.v. guide 
cannula under pentobarbital anaesthesia (Narcovet, $60 \mathrm{mg} / \mathrm{kg}$ ). The electrodes were placed on the surface of the cortex, one in the frontal region (coordinates with the skull surface flat and bregma zero-zero: A 2.0, L 3.5) and the other in the parietal region (A -6.0, L 4.0). The ground electrode was placed in the cerebellum. A polyethylene cannula (inner diameter $0.4 \mathrm{~mm}$, outer diameter $0.8 \mathrm{~mm}$ ) was placed contralaterally to the electrodes in the left lateral ventricle (A 0.7, L -1.3) at a depth of $3.5 \mathrm{~mm}$ from the skull surface. Upon the termination of the experiment, the rats were killed by an overdose of pentobarbital, and the location of the cannula was verified. After the surgery the animals were allowed to recover for 1 week; afterwards, they were put into a transparent recording cage $(25 \times 25 \times 35 \mathrm{~cm})$. Finally, the rats were connected to EEG leads and habituated for $24 \mathrm{~h}$. The $\kappa$ receptor agonists U50,488H (Upjohn Company), U69,593 (Upjohn Company) and PD117,302 (Parke and Davis) were dissolved in Ringer's solution and injected i.c.v. in a volume of $5 \mu 1$ twice (cumulative dose), first with a low dose $(50 \mu \mathrm{g})$ and $1 \mathrm{~h}$ later with a higher dose $(150 \mu \mathrm{g})$. In other experiments U50,488H was dissolved in physiological saline and injected s.c. only once. Control rats received Ringer's solution i.c.v. or physiological saline s.c., respectively. Nor-BNI (Research Biochemicals Internationals, Natick, MA, USA) was injected in a dose of $10 \mu \mathrm{g}, 18 \mathrm{~h}$ before EEG registration. In a separate experiment, the rats were injected with U50,488H, U69,593, PD1 17,302 (150 $\mu \mathrm{g} / 5 \mu$ l i.c.v.) or Ringer $(5 \mu$ li.c.v. $) 1 \mathrm{~h}$ before injection of the specific $\mu$ receptor agonist DAMGO (Sigma) in a dose of $0.7 \mu \mathrm{g} / 5 \mu$ i.c.v. EEG was recorded for $1 \mathrm{~h}$ after i.c.v. or $2 \mathrm{~h}$ after s.c. drug administration. The rats were observed from an adjacent room and the time of the exploratory (exploration, sniffing, rearing), automatic (eating, drinking, grooming) and passive (sleeping, immobility) behaviour was scored using a behavioural recording system (The Observer, Noldus, 1991).

The majority of the rats were used only once; in some cases they were used for a second time after no less than 6 days. The EEG with frequencies between 1 and $70 \mathrm{~Hz}$ was monitored, digitalized and stored for off-line analysis using an ACODAS system as described previously [6]. The number of trains of SWDs and their mean duration per subject per hour were determined and these data were statistically analysed by ANOVA followed by Duncan's test.

U50,488H (50 and $150 \mu \mathrm{g}$ i.c.v.) decreased dosedependently the number of SWD, and tended to decrease their mean duration. U69,593 (50 and $150 \mu$ g i.c.v.) also dose-dependently decreased the number of SWD; when used in a higher dose, it significantly shortened the mean duration of SWD. PD117,302 in a dose of $50 \mu \mathrm{g}$ i.c.v. showed no effect; however, given in a dose of $150 \mu \mathrm{g}$, it significantly decreased both the number and mean duration of SWD (Fig. 1). None of the $\kappa$ agonists administered
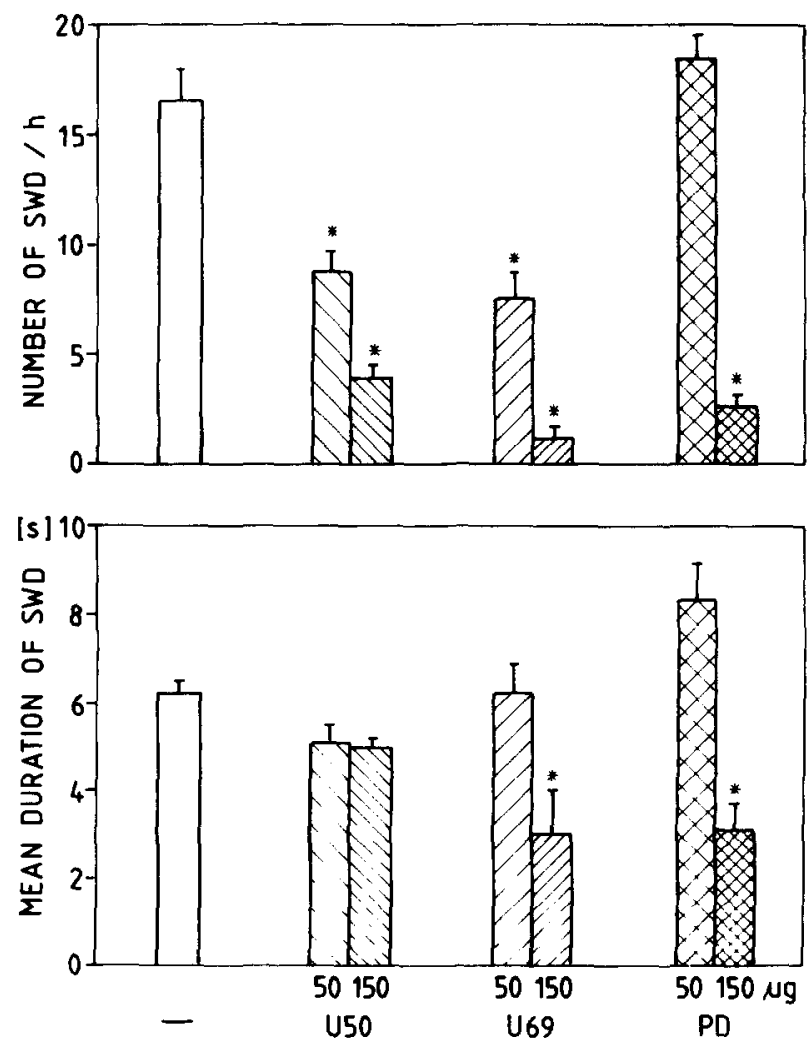

Fig. 1. The effect of $\kappa$ receptor agonists: U50,488H (U50), U69,593 (U69) and PD117,302 (PD) injected i.c.v. first at a low dose $(50 \mu \mathrm{g} / 5 \mu \mathrm{l})$ and $1 \mathrm{~h}$ later at a higher dose $(150 \mu \mathrm{g} / 5 \mu \mathrm{l})$ on the number of trains of spike wave discharges (SWD) and their mean duration. The results are the mean \pm SEM of $6-12$ rats per group. ${ }^{*} P<0.05$ versus control.

i.c.v. in a dose of $50 \mu \mathrm{g}$ changed the behaviour, however, a dose of $150 \mu \mathrm{g}$ evoked a decrease in the automatic behaviour and slightly enhanced the passive behaviour.

$\mathrm{U} 50,488 \mathrm{H}$ injected in doses of 10 and $30 \mathrm{mg} / \mathrm{kg}$ s.c. decreased the number of SWD in a dose- and timedependent manner, the effect being more pronounced at the second hour of EEG registration (Table 1). No significant changes in mean duration of SWD were noted after the U50,488H s.c. administration (data not shown). Peripheral injections of 30 and $50 \mathrm{mg} / \mathrm{kg}$ of $U 50,488 \mathrm{H}$ reduced the time of explorative and automatic behaviour and enhanced passive behaviour in a dose-dependent manner. At the highest dose used, the rats were almost completely immobile.

Nor-BNI injected i.c.v. in a dose of $10 \mu \mathrm{g} 18 \mathrm{~h}$ before EEG registration increased the number of SWD (control $18.6 \pm 2.9$, Nor-BNI $28.3 \pm 3.0, P<0.05$ ANOVA). No changes in the duration of SWD (control $6.2 \pm 0.3$, NorBNI $5.2 \pm 0.3$ ), as well as in behaviour, were observed after Nor-BNI administration.

In agreement with a previous study [6], DAMGO $(0.7 \mu \mathrm{g} / 5 \mu \mathrm{l}$ i.c.v.) markedly increased the number of SWD. This effect was significantly attenuated in rats pretreated with U50,488H and PD117,302 (Fig. 2). In rats 
Table 1

The effects of subcutaneous injection of U50,488H (U50) in different doses on the number of trains of spike wave discharges (SWD)/subject per hour in WAG/Rij rats

\begin{tabular}{llc}
\hline Dose (mg/kg) & 1st hour after U50 & 2nd hour after U50 \\
\hline $0.9 \% \mathrm{NaCl}$ & $33.7 \pm 3.0$ & $30.3 \pm 2.3$ \\
U50 (10) & $27.3 \pm 4.5$ & $24.9 \pm 6.4$ \\
U50 (30) & $20.0 \pm 3.1$ & $9.8 \pm 1.1^{*}$ \\
U50 (50) & $16.8 \pm 5.1^{*}$ & $10.6 \pm 2.6^{*}$ \\
\hline
\end{tabular}

Results are the mean \pm SEM for $6-12$ rats per group. ${ }^{*} P<0.05$.

pretreated with U69,593 the effect of DAMGO on the number of SWD tended to decrease, but did not reach statistical significance. DAMGO alone or after pretreatment with U50,488H and U69,593 had no effect on mean duration of SWD (data not shown). The mean duration of SWD after DAMGO and PD117,302 was significantly shorter compared to controls $(6.5 \pm 0.6$ and $3.8 \pm 0.5$, respectively, $P<0.05$ ).

All the $\kappa$ agonists used in our study decreased the number and mean duration of SWD. This anti-absence effect was also observed after central and, as was shown for $\mathrm{U} 50,488 \mathrm{H}$, peripheral administration. Inhibition of both the number and mean duration of SWD indicates that stimulation of the $\kappa$ receptor prevents generation of SWD, and inhibits the ongoing seizure activity in WAG/Rij rats. The effect appears, despite the fact that the substances studied evoke a visible calming effect which facilitates development of SWD. The latter are found mainly during slow-wave sleep and passive wakefulness [19]. Therefore it is unlikely that the suppression of absence seizures should stem from the effect of the $\kappa$ agonists on the animal behaviour.

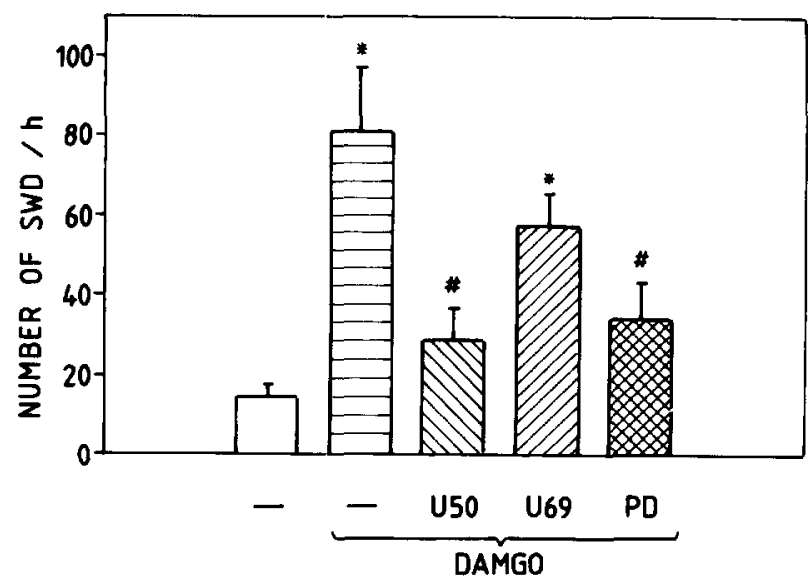

Fig. 2. The effect of DAMGO injected at a dose $0.7 \mu \mathrm{g} / 5 \mu \mathrm{l}$ i.c.v. $1 \mathrm{~h}$ after $150 \mu \mathrm{g} / 5 \mu \mathrm{l}$ i.c.v. of U50,488H (U50), U69,593 (U69) and PD117,302 (PD) on the number of trains of spike wave discharges (SWD) and their mean duration. The results are the mean \pm SEM of 6-9 rats per group. ${ }^{*} P<0.05$ versus control, ${ }^{\#} P<0.05$ versus DAMGO alone.
Agonists of $\kappa$ opioid receptors are efficient anticonvulsants in spontaneous and electrically or chemically induced generalized convulsive seizures, which are animal models of grand mal epilepsy [17,20]. It should be noted that some drugs used for the treatment of grand mal seizures, such as phenytoin, have no effect or even aggravate absence seizures; therefore it seems that $\boldsymbol{\kappa}$ agonists develop unique pharmacological characteristics, being effective in both types of epilepsy. The neurochemical mechanism of protective effects of $\boldsymbol{\kappa}$ agonists in rats with spontaneous absence epilepsy remains unknown. One of possible explanation is an inhibitory influence of $\boldsymbol{\kappa}$ agonists on excitatory amino acids [20], which are known to play an important role in regulation of absence seizures in WAG/Rij rats [8]. Stimulation of $\kappa$ receptors has an inhibitory effect on voltage-dependent calcium channels, but the significance of this mechanism in the regulation of absence seizures will require further studies.

In our experiment, Nor-BNI, a specific $\boldsymbol{\kappa}$ opioid antagonist [11], caused an increase in the number of SWD. As was shown in our previous study, naloxone also promoted the occurrence of SWD [6]. The latter effect was likely to be mediated by antagonism towards $\kappa$ receptors, since specific antagonists of $\mu$ and $\delta$ receptors $(\beta$-funaltrexamine and naltrindole) had no effect on SWD [6]. These facts suggest that endogenous opioids, which act through the $\kappa$ receptors (e.g. prodynorphin-derived peptides), tonically control the initiation of absence seizures in WAG/Rij rats. Indeed, a biochemical study showed that, in comparison with non-epileptic controls, epileptic WAG/Rij rats showed changes in both the proenkephalin and the prodynorphin peptides level as well as respective mRNAs in discrete brain areas $[5,7]$.

In our model, $\kappa$ receptor agonists not only act in a way opposite to $\mu$ receptor agonists $[3,6]$, but can also attenuate the DAMGO-induced increase in the number of SWD. This finding is in line with reports that $\kappa$ opioid receptor agonists can antagonize some effects of $\mu$ agonists, i.e. dynorphin has been found to antagonize the effects of morphine in a variety of tests in vivo $[4,18]$, similarly, $\mathrm{U} 50,488 \mathrm{H}$ antagonizes the effect of ethorphine on the fluorothyl-induced seizures threshold [10] and the bladder effects of $\mu$ agonists at spinal sites in rats [15]. Our data provide further evidence that activation of $\mu$ and $\kappa$ opioid receptors may, under certain conditions, influence the excitability of the nervous system in opposite ways.

In conclusion, our data indicate that $\boldsymbol{\kappa}$ opioid receptor agonists may be regarded as potential drugs against absence seizures, moreover, they suggest that $\kappa$ receptors are tonically involved in the suppression of SWD generation in WAG/Rij rats.

This study was supported by the TNO Research Committee on Epilepsy, the Division for Health Research, TNO CLEO grants A.73 and A.83, and the Committee for Scientific Research, KBN 4162691 01, Warszawa. 
[1] Coenen, A.M.L. and van Luijtelaar, E.L.J.M., The WAG/Rij rat model for absence epilepsy: age and sex factors, Epilepsy Res., 1 (1987) 297-301.

[2] Frenk, H., Pro- and anticonvulsant actions of morphine and endogenous opioids; involvement and interactions of multiple opiate and non-opiate systems, Brain Res. Rev., 6 (1983) 197-210.

[3] Frey, H.H. and Voits, M., Effect of psychotropic agents on a model of absence epilepsy in rats, Neuropharmacology, 30 (1991) 651-656

[4] Friedman, H.J., Jen, M.F., Chang, J.K., Lee, N.N. and Loh, H.H., Dynorphin: A possible modulatory peptide on morphine and $\beta$ endorphin analgesia in mouse, Eur. J. Pharmacol., 69 (1981) 357360.

[5] Lasoń, W., Przewłocka, B., van Luijtelaar, E.L.J.M., Coenen, A.M.L. and R. Przewłocki., Endogenous opioid peptides in brain and pituitary of rats with absence epilepsy, Neuropeptides, 21 (1992) $147-152$.

[6] Lasoń, W., Przewłocka, B., van Luijtelaar, E.L.J.M., Coenen, A.M.L. and Przewłocki, R., Effects of $\mu$ and $\delta$ opioid receptor agonists and antagonists on absence epilepsy in WAG/Rij rats, Neuropharmacology, 33 (1994) 161-166.

[7] Lasoń, W., Przewłocka, B., van Luijtelaar, E.L.J.M., Coenen, A.M.L. and Przewłocki, R., Proenkephalin and prodynorphin mRNA level in brain of rats with absence epilepsy, Neuropeptides, 27 (1994) 343-347.

[8] Peeters, B.W.M.M., Rijn van, C.M., Vossen, J.M.H. and Coenen A.M.L., Involvement of NMDA receptors in non-convulsive epilepsy in WAG/Rij rats, Life Sci., 47 (1990) 523-529.

[9] Peeters, B.W.M.M., Spooren, W.P.J.M., van Luijtelaar, E.L.J.M. and Coenen, A.M.L., The WAG/Rij model for absence epilepsy: anticonvulsant drug evaluation, Neurosci. Res. Commun., 2 (1988) 93-97.

[10] Porreca, F. and Tortella, F.C., Differential antagonism of $\mu$ agonists by U50,488H in the rat, Life Sci., 41 (1987) 2511-2516.
[11] Portoghese, P.S., Lipkowski, A.W. and Takemori A.E., Binaltorphimine and nor-binaltorphimine, potent and selective $\kappa$-opioid receptor antagonists, Life Sci., 4 (1987) 1287-1292.

[12] Przewłocka, B., Machelska, H. and Lasoń, W., Kappa opioid receptor agonists inhibit the pilokarpine-induced seizures and toxicity in the mouse, Eur. Neuropsychopharmacol., 4 (1994) 527-533.

[13] Przewłocka, B., Stala, L., Lasoń, W. and Przewłocki, R., The effects of various opiate receptor agonists on the seizure threshold in the rat; is dynorphin an endogenous anticonvulsant?, Life Sci., 33 (Suppl. 1) (1983) 595-598.

[14] Ramabadran, K. and Bansinath, M., Endogenous opioid peptides and epilepsy, Int. J. Clin. Pharmacol. Ther. Toxicol., 28 (1990) 47-62.

[15] Sheldon, R.J., Nunan, L. and Porreca F., U50,488H differentially antagonizes the bladder effects of $\mu$ agonists at spinal sites, Eur. J. Pharmacol., 146 (1988) 229-235.

[16] Tortella, F.C., Endogenous opioid peptides and epilepsy: quieting the seizing brain?, Trends Pharmacol. Sci., 9 (1988) 366-372.

[17] Tortella, F.C., Robles, L. and Holaday, J.W., U-50,488H, a highly selective $\kappa$ opioid: anticonvulsant profile in rats, J. Pharmacol. Exp. Ther, 237 (1986) 49-53.

[18] Tulunay, F.C., Jen, M.F., Chang, J.K., Loh, H.H. and Lee, N.N., Possible regulatory role of dynorphin on morphine- and $\beta$ endorphin-induced analgesia, J. Pharmacol. Exp. Ther., 219 (1981) 296-298.

[19] Van Luijtelaar, E.L.J.M. and Coenen, A.M.L., The WAG/Rij model for generalized absence seizures. In J. Manelis, E. Bental, J.N. Loeber and F.E. Dreifuss (Eds.), Advances in Epileptology, Vol. 17, Raven Press, New York. 1989, pp. 78-83.

[20] Von Voigtlander, P.F., Hall, E.D., Kamacho-Ochoa, M., Lewis, R. and Triezenberg, H.J., U-54494A: a unique anticonvulsant related to $\mathcal{K}$ opioid agonists, J. Pharmacol. Exp. Ther., 243 (1987) 542547. 